Available online at : http://journal.unj.ac.id/unj/index.php/gjik

Gladi : Jurnal Ilmu Keolahragaan 10 (02) 2019, 112-120

Permalink/DOI: https://doi.org/10.21009/GJIK.102.05

\title{
ANALISIS UNIFIKASI PADA GERAK DASAR RUNNING ABC MAHASISWA FIO 2018 UNIVERSITAS NEGERI JAKARTA
}

\author{
Ricky Susiono' ${ }^{1}$, Hernawan ${ }^{2}$ \\ ${ }^{1}$ Program Studi Pendidikan Kepelatihan Olahraga, Universitas Negeri Jakarta, \\ Rawamangun, Kec. Pulo Gadung, Kota Jakarta Timur, Daerah Khusus Ibukota \\ Jakarta 13220 \\ ${ }^{2}$ Program Studi Olahraga Rekreasi, Universitas Negeri Jakarta, Rawamangun, Kec. \\ Pulo Gadung, Kota Jakarta Timur, Daerah Khusus Ibukota Jakarta 13220 \\ Corresponding Email: rickysusiono@gmail.com
}

\begin{abstract}
Abstrak. Mahasiswa olahraga yang baru masuk universitas pada umumnya belum menguasai pengetahuan gerak dasar Running ABC. Begitu juga mahasiswa Fakultas Ilmu Olahraga (FIO) 2018 Universitas Negeri Jakarta. Ini bisa dilihat dari hasil tes fisik dan keterampilan mahasiswa baru FIO UNJ. Rata-rata mahasiswa baru gagal dalam tes kemampuan gerak dasar. Mereka banyak gagal dalam kemampuan dasar seperti kemampuan berlari, melompat, melempar. Mahasiswa saat sekolah hanya mendapatkan pelatihan konvensional mengenai gerak dasar Running ABC. Kegagalan dalam tes kemampuan dasar Running ABC ini seharusnya dapat dihindari jika mereka mendapatkan metode dan pelatihan yang tepat. Oleh karena itu analisis menggunakan metode Unifikasi mengenai kemampuan gerak dasar perlu dilakukan. Metode unifikasi adalah salah satu metode dan pelatihan memperkenalkan para mahasiswa baru memahami gerak dasar Running ABC yang baik, efisien, harmonis. Dengan analisis unifikasi dapat mendeskripsikan kesalahan-kesalahan gerak dasar yang sering dilakukan mahasiswa saat latihan.
\end{abstract}

Kata kunci : running abc, gerak dasar, mahasiswa, unifikasi

\begin{abstract}
Sports students who have just entere d university in general have not yet mastered the basic knowledge of Running ABC. Likewise, students of the Faculty of Sports (FIO) 2018 Jakarta State University. This can be seen from the results of physical tests and skills of new students at FIO UNJ. The average new student fails the basic ability test. They fail a lot in basic abilities such as the ability to run, jump, throw. Students at school only get conventional training on the basic movements of Running ABC. Failure in Running $A B C$ 's basic skills tests should be avoided if they get the right methods and training. Therefore an analysis using the Unification method regarding basic mobility needs to be done. The unification method is one of the methods and training introducing new students to understand the basic movements of Running ABC that are good, efficient, harmonious. With the unification analysis can describe the basic motion mistakes that are often made by students during practice.
\end{abstract}

Keywords: Unification, Running ABC, Basic Motion, Student

\section{PENDAHULUAN}

Peningkatan prestasi olahraga perlu dilakukan pembinaan sedini mungkin melalui pencarian dan pembentukan bakat, pendidikan, serta pelatihan olahraga. Pendidikan jasmani yang ada di sekolah memiliki tujuan untuk membangun kesehatan, sportivitas, disiplin, ketahanan dan jiwa yang kuat dalam upaya membangun manusia yang unggul dan berdaya saing. Oleh karena itu, olahraga harus 
diberdayakan baik itu di instansiinstansi, masyarakat luas maupun di lingkungan pendidikan (Wardianto, 2016)

Pengetahuan utama dalam olahraga adalah gerak (Hernawan, Sukarya, \& Solahuddin, 2019). Namun tak semua orang memiliki pengetahuan mengenai gerak dasar yang baik. Kemampuan gerak dasar juga dikatakan kemampuan dasar multilateral. Kemampuan dasar multilateral seseorang sangat penting untuk menunjang kemampuan yang lain dalam konteks gerak (Sujarwo, 2012). Semakin bagus kemampuan dasar multilateral seseorang, maka diharapkan semakin bagus kemampuan geraknya. Sebaliknya apabila kemampuan dasar multilateral seseorang kurang bagus, dimungkinkan kemampuan geraknya akan mengalami kendala.

Rata-rata dari mahasiswa memiliki kecenderungan kemampuan gerak dasar yang kurang baik. Peneliti menilai rendahnya penguasaan keterampilan teknik dasar para mahasiswa sangat dipengaruhi oleh gerak dasar motoriknya. Karena didalam penguasaan keterampilan teknik dasar, belajar motorik yang pernah dilakukan mahasiswa pada waktu yang sebelumnya ikut mempengaruhi proses penguasaan penampilan dalam tes fisik dan keterampilan. Banyak faktor yang menyebabkan mahasiswa tidak memiliki kemampuan gerak dasar yang baik. Salah satunya adalah kebanyakan dari mahasiswa mendapatkan pelatihan konvensional saat di sekolah. Kegagalan dalam tes kemampuan dasar ini seharusnya dapat dihindari jika mereka mendapatkan metode dan pelatihan yang tepat.

Dari observasi yang dilakukan peneliti sebelumnya, pada umumnya mahasiswa yang menempuh pendidikan keolahragaan di universitas sering gagal dalam tes fisik dan keterampilan. Ini juga yang terjadi pada mahasiswa Fakultas Ilmu Olahraga (FIO) 2018 Universitas Negeri Jakarta. Kegagalan dalam tes fisik dan keterampilan dikarenakan kemampuan gerak dasar Running ABC mahasiswa FIO 2018 jauh di bawah ratarata. Padahal kemampuan gerak dasar ini merupakan prinsip penting latihan yang wajib dimiliki oleh mahasiswa FIO 2018. Mahasiswa FIO 2018 adalah calon atlet, pelatih, instruktur, dan guru olahraga yang dapat menunjang prestasi nasional dan internasional di bidang olahraga.

Peningkatan

kapasitas pengetahuan mengenai kemampuan gerak dasar dapat dilakukan melalui metode unifikasi. Metode Unifikasi mampu meningkatkan pengetahuan mahasiswa FIO mengenai gerak dasar yang baik, efisien dan harmonnis. Dari pengamatan peneliti, seseorang yang mengikuti latihan pengembangan kemampuan gerak dasar, seperti berjalan, berlari, melompat, melempar, menangkap, berguling, dan keseimbangan. Nantinya seseorang akan memiliki sikap tubuh dan kemampuan koordinasi yang baik. Latihan dasar Running $\mathrm{ABC}$ ini membantu dan menunjang setiap gerakan yang dilakukan mahasiswa saat tes fisik dan keterampilan. Dengan mengembangkan berbagai jenis kemampuan biomotor (daya tahan, kecepatan, kekuatan, kelenturan, dan sebagainya) seseorang dapat lebih mudah menguasai berbagai gerakan secara harmonis yang dapat difokuskan pada salah satu cabang olahraga yang nantinya akan ditekuni oleh mahasiswa FIO 2018.

\section{Unifikasi}

Secara harfiah, kata unifikasi berarti penyatuan atau kesatuan. Kata unifikasi diambil dari metode yang ada dalam ilmu bela diri Aikido. Peneliti 
memperkenalkan istilah ShinshinToitsu-Do yang artinya menyatukan hati dan badan. Istilah ini ditemukan oleh soshu Koichi Tohei dengan motto "Yang dapat dipakai di dalam kehidupan seharihari”, artinya banyak cara atau ajaran yang diperkenalkan bagaimana hidup damai yang penuh dengan kebahagiaan. Senam unifikasi adalah cara melatih kesatuan dalam kondisi apa pun, baik dalam keadaan berdiri maupun duduk (Tohei, 2001). Metode unifikasi merupakan latihan yang menyelaraskan gerakan tubuh dan pikiran. Gerakan yang selaras dan menjadi satu dalam asas bergerak dapat menciptakan gerakan yang cepat, efisien, dan aman. Latihan unifikasi sangat membantu dalam kesadaran gerak yang dapat membuat seseorang mempunyai kualitas gerak yang baik.

Dalam proses unifikasi, dikenal adanya tahapan dari tidak terbiasa menjadi terbiasa dan dari terbiasa menjadi ahli. Setelah itu, secara berangsur-angsur keahlian akan meningkat. Secara umum terdapat tiga tahapan dalam mempelajari unifikasi, antara lain Tahap pertama, mempelajari sikap dan gerakan dalam rangka memperoleh dasar gerakan yang baik. Dalam hal ini pemula seharusnya memiliki pemahaman yang jelas tentang sikap tangan, gerak tangan, sikap langkah, gerak kaki, sikap tubuh, gerak tubuh, pandangan mata, dan sebagainya. Melalui pemahaman tersebut, gerakan dapat dijalankan dengan benar dan halus sehingga sikap tubuh menjadi mantap dan lembut. Tahap kedua, mempelajari pola umum dari variasi-variasinya. Tahap ini bertujuan membuat gerakan saling berhubungan dan halus, gerak atas dan bawah saling mengikuti secara alami dan terkoordinasi. Tahap ketiga, menekankan pada hati dan perasaan, yakni bagaimana menyesuaikan gerak agar harmonis dan menggunakan pikiran dan hati menjadi satu kesatuan. Beberapa orang menganggap tahapan ini sebagai "membangkitkan energi yang menghasilkan kekuatan".

Berikut ini beberapa hal yang patut mendapat perhatian untuk mencapai ketiga tahapan tersebut. 1). Tubuh dijaga tegak.Dalam berlatih, tubuh harus dijaga agar tetap unifikasi. Usahakan sikap tubuh senyaman mungkin, caranya dengan menjaga posisi tubuh agar tulang belakang lurus. Dengan posisi seperti ini, kaki, lengan dan kepala akan tegak dengan sendirinya. Dengan mengabaikan bagian tertentu dan melakukan sikap yang salah dapat menyebabkan kehilangan salah satu prinsip dasar unifikasi. 2).Kesinambungan, Setelah sikap-sikap gerakan membentuk dasar tertentu, cobalah untuk membuat kesinambungan yang baik di antara tiap-tiap gerakan. Setiap sikap gerakan harus dirangkai dengan baik dan benar. Akhir dari satu sikap merupakan awal dari sikap berikutnya. Setelah mengembangkan keahlian, pemula dapat melakukan beberapa gerakan secara terpisah lalu menggabungkannya sehingga setiap interval di antara sikap-sikap menjadi hidup dan berirama. Lakukan gerakan berikutnya dengan cepat dan jagalah kesinambungan antara depan dan belakang, yang semuanya terhubung dengan baik tanpa jeda. 2). Koordinasi, Berlatih unifikasi berarti melatih seluruh tubuh. Dibutuhkan irama tinggi dan rendah saling mengikuti, berintegrasi, dan tidak terputus. Pergerakan seluruh bagian tubuh terkoordinasi. Dalam mengayunkan tangan misalnya, perputaran pinggang membawa tangan berayun dan telapak tangan berputar dengan tangan. Kedua kaki menyangga tubuh berputar ke kiri dan ke kanan. Kepala juga berputar secara alami mengikuti gerak tubuh. Pada saat yang sama, mata melihat ke arah tangan yang 
sedang bergerak. Dengan melakukan semua ini, berarti membuat gerakan lengkap dari seluruh tubuh karena adanya koordinasi yang baik dari seluruh bagian.3). Konsentrasi dan fokus Ketika berlatih unifikasi, fokuskan hati dan pikiran pada seluruh rangkaian gerak. Pikiran memodifikasi pusat saraf, menekan fungsi organ-organ, dan mempertinggi efek kepekaan. Semua itu mempunyai efek langsung dalam proses unifikasi.

\section{Running ABC}

Athletic Basic Coordination adalah kepanjangan dari Running $\mathrm{ABC}$ yang diartikan ke dalam bahasa Indonesia adalah latihan kordinasi gerak dasar atletik. Model latihan running ABC sangat cocok terutama untuk menunjang dan mengarah pada nomor lari jarak pendek terutama nomor sprint $100 \mathrm{~m}, 200 \mathrm{~m}, 400 \mathrm{~m}$, lari gawang, lari sambung atau estafet dan lain-lain. Macam-macam dan nama latihan dalam running $\mathrm{ABC}$ ada banyak sekali kurang lebih mungkin sampai 25 macam jenis latihan. Running $\mathrm{ABC}$ adalah salah satu model latihan yang sangat bagus dipilih untuk kemudian diberikan dalam proses pembelajaran di sekolah menengah pertama hingga perguruan tinggi sehingga menghasilkan suatu out put yang memuaskan dengan dibuktikan oleh keterampilan siswa yang meningkat dan berprestasi (Ramadhanova, 2019)

Teori tentang Running ABC adalah sebagai berikut (Priyono, 2016).

\section{Acceleration Balance Coordination Running (Abc running)}

Teknik latihan abc running di bagi melingkupi latihan gerakan tungkai, gerakan lutut dan gerakan tangan sebagai berikut : 1).Gerakan tungkai, Diawali dengan sikap badan berdiri tegap kedua lengan bebas kesamping badan kemudian lakukan gerakan di tempat dengan mengangkat tumitkemudian letakan kembali ditanah, ujung kaki tetap nempel ke tanah bersamaan dengan itu kedua lengan ditekuk membentuk sudut 90 derajat dan digerakan mengikuti gerakan irama tungkai. 2). Teknik gerakan lutut abc running Diawali dengan sikap berdiri tegak, kemudian lari ditempat dengan kedua kaki diluruskan kedepan secara bergantian kaki diangkat berlahan-lahan kemudian mengikuti irama semakin cepat, gerakan ini bisa dilakukan kirakira 10-15 meter. Gerakan juga bisa diganti dengan tendangan kaki secara bergantian kepantatatau kearah belakang badan gerakan ini bisa dilakukan dengan cara melangkah maju kira-kira 10-15 meter. 3). Gerakan tungkai dan tangan. Diawali dengan sikap berdiri tegak, kedua lengan ditekuk membentuk sudut 90 derajat. Kemudian lari ditempat dengan gerakan mengangkat lutut tinggi, setinggi pinggul disertai geakan ayunan lengan. Ketika tungkai kanan diangkat dengan lutut setinggi pinggul lengan kiri diayun kedepan dengan kuat setinggi bahu dan kecepatan di tangan depan dada. Lakukan gerakan kedepan dengan gerekan yang cepat dengan jarak 10-15 meter.

\section{Konsep Dari Acceleration Balance Coordination Running}

Serangkaian gerak lari dalam waktu yang bersamaan dan hampir bersamaan dengan harmonis yang di dalamnya tediri dari unsur geakan lari acceleration balance coordination running, yang kian hari, kian meningkat kecepatannya. Pembelajaran ini digunakan untuk memperbaiki kordinasi dan teknik lari sprint, berlatih bagian demi bagian secara benar dan secara perlahan dalam massa latihan secara formal. 


\section{Pembelajaran Teknik Lari Sprint Dengan Latihan Gerak Lari ABC}

Menurut Hendrayana (2007)

Istilah gerak lari abc sebenarnya lebih diutamakan pada gerak yang bervariasi dan disusun berdasarkan sistematika berbagai bentuk gerakan kaki dari yang mudah ke yang sukar. Pembelajaran ini digunakan untuk memperbaiki koordinasi dan teknik lari sprint. Metode yang dapat diterima untuk mengembangkan teknik sprint adalah berlatih bagian secara benar dan secara perlahan dalam masa latihan secara formal. Segera tingkatkan kecepatan berlari sesudah melakukan gerakan dengan irama yang benar. Jarak yang dianjurkan adalah 10-15 meter dengan 2 sampai 3 kali pengulangan. Kamu boleh berjalan ketika kembali ketempat semula

\section{Metode dan Latihan}

Menurut Surachmad (1994)

metode adalah cara yang di dalam fungsinya merupakan alat untuk mencapai tujuan, makin baik metode itu makin efektif pula pencapaian tujuan. Sedangkan Supandi (1992) mengemukakan bahwa metode adalah prosedur atau operasi mencapai tujuan. Sementara itu definisi latihan menurut Harisenjaya (1993) yaitu pengulangan dari beberapa gerakan tertentu, secara sistematik dan teratur, berirama dengan tujuan untuk memelihara atau meningkatkan kemampuan fisik seseorang, dalam mencapai prestasi maksimal. Berdasarkan definisi latihan menurut Harisenjaya tersebut jika seseorang melakukan latihan dengan teratur, sistematis, sesuai dengan kebutuhan yang diperlukan dan menambah beban latihan maka akan mencapai prestasi yang maksimal. Sedangkan, Haag dan Krempel (1987) mendefinisikan latihan sebagai jumlah semua rangsangan yang dilaksanakan pada jarak-jarak waktu tertentu dengan tujuan untuk meningkatkan prestasi, dan latihan tersebut dimaksudkan untuk mencapai perubahan atau penyesuaian fungsional dan morfologis organismenya.

Maka dari itu latihan tidak hanya menyajikan pengulangan secara mekanis saja, tetapi juga mengulang secara sadar menurut kemauan dan terarahkan. Sedangkan Proses latihan dilakukan secara sadar, terarah, melalui pengulangan-pengulangan, dengan demikian akan timbul otomatisasi gerak/kerja, sehingga dapat mempengaruhi kondisi fisik. Woeryanto (1991) mendefinisikan latihan dalam bukunya bahwa latihan adalah suatu proses yang sistematis dan harus menganut prinsip-prinsip latihan tertentu sehingga organisme dan mekanisme neorophysiologi atlet akan bertambah baik. Berdasarkan kedua definisi dari beberapa sumber diatas dapat disimpulkan bahwa metode latihan adalah kegiatan yang dilakukan dalam jangka waktu lama serta sistematik dan progresif sesuai dengan tingkat kemampuan individu, memiliki tujuan untuk membentuk fungsi fisiologis dan psikologis yang memenuhi syarat bagi tugas-tugas kegiatan olahraga.

\section{METODE PENELITIAN}

\section{Jenis Desain Penelitian}

Jenis penelitian yang dilakukan adalah penelitian deskriptif dengan pendekatan survey, yaitu penelitian yang bertujuan untuk menguraikan atau menggambarkan tentang karakteristik dari suatu keadaan atau objek penelitian yang dilakukan melalui pengumpulan data (Prasetyo dan Miftahuljannah, 2007). Penelitian ini digunakan untuk mengetahui gerak dasar yang dimiliki 
oleh mahasiswa FIO 2018 saat latihan Running ABC.

\section{Populasi dan Sampel Penelitian}

Populasi pada penelitian ini adalah Mahasiswa Fakultas Ilmu Olahraga (FIO) 2018 dengan jumlah 40 (empat puluh) mahasiswa. Ke 40 (empat puluh) mahasiswa ini merupakan mahasiswa yang mengambil matakuliah atletik 1. Oleh karena jumlah populasinya sedikit yaitu dibawah 100 (seratus) orang maka teknik sampel yang digunakan dalam penelitian ini adalah Teknik Sampel Sensus yaitu suatu cara untuk mengumpulkan data dengan dikumpulkannya seluruh elemen populasi dan data yang didapatkannya merupakan data yang sebenarnya (Diposumarto, 2012) sehingga jumlah sampel penelitian adalah sama dengan jumlah populasi sebesar 40 (empat puluh) mahasiswa.

\section{Jenis dan Sumber Data}

Jenis data yang digunakan dalam penelitian ini adalah data primer. Data primer adalah data yang berasal dari sumber asli atau dari sumber pertama. Data ini tidak tersedia dalam bentuk yang terkompilasi ataupun dalam bentuk file-file. Data ini harus dicari melalui nara sumber atau melalui responden yaitu orang yang kita jadikan obyek penelitian atau orang yang kita jadikan sebagai sarana untuk mendapatkan informasi atau data (Sarwono, 2006). Sedangkan sumber data dalam penelitian adalah subjek darimana data diperoleh (Arikunto, 2010)., sumber data yang utama dalam penelitian kualitatif adalah kata-kata dan tindakan, selebihnya adalah data tambahan seperti dokumen dan literature lain (Moleong, 2005). Sumber data dalam penelitian ini adalah proses gerak dasar running $\mathrm{ABC}$ mahasiswa FIQ 2018 Universitas Negeri
Jakarta dengan menggunakan metode Unifikasi.

\section{Teknik Pengumpulan Data}

Teknik pengumpulan data merupakan langkah yang paling utama dalam penelitian, karena tujuan utama dari penelitian adalah mendapatkan data. Tanpa mengetahui teknik pengumpulan data, maka peneliti tidak akan mendapatkan data yang memenuhi standar data yang ditetapkan (Sugiyono, 2009). Teknik pengumpulan data yang digunakan dalam penelitian ini adalah dengan menggunakan teknik observasi dan dokumentasi. Observasi menurut Sutopo (2006) digunakan untuk menggali data dari sumber data yang berupa peristiwa, tempat atau lokasi, dan benda, serta rekaman gambar. Sementara itu, Hadari (2012)) mengartikan observasi adalah pengamatan atau pencatatan secara sistemik terhadap gejala yang tampak pada objek penelitian. Observasi dan dokumentasi dilakukan saat mahasiswa Fakultas Ilmu Olahraga Program Studi Kepelatihan Olahraga menghadiri mata kuliah atletik 1. Dalam penelitian kualitatif, dokumentasi merupakan pelengkap dari penggunaan teknik observasi yang digunakan. Hasil pengumpulan data dari observasi akan lebih kredibel atau dapat dipercaya apabila didukung dengan dokumentasi (Sugiyono, 2009). Dokumentasi dalam penelitian ini adalah berupa foto-foto atau gambar-gambar dan video mengenai serangkaian kegiatan yang dilakukan peneliti saat berada di lapangan.

\section{Teknik Analisa Data}

Analisis data adalah upaya yang dilakukan dengan cara mengorganisasikan data, memilahnya menjadi satuan yang dapat dikelola, mencari, dan menemukan pola, 
menemukan apa yang paling penting dan yang dipelajari, dan memutuskan yang dapat diceritakan kepada orang lain (Moleong, 2005). Analisis masalah telah dimulai sejak merumuskan dan menjelaskan masalah, sebelum terjun ke lapangan, dan berlangsung terus sampai penulisan hasil penelitian (Sugiyono, 2009). Teknik analisis data yang digunakan dalam penelitian ini adalah teknik analisis interaktif menurut Sugiyono , bahwa aktivitas dalam analisis data kualitatif dilakukan secara interaktif dan berlangsung secara terus-menerus sampai tuntas, sehingga datanya sudah jenuh

\section{HASIL DAN PEMBAHASAN}

Running $\mathrm{ABC}$ menjadi hal yang wajib dikuasai bagi calon pelatih cabang olahraga. Running ABC yang baik dan benar mampu meningkatkan teknik lari bagi atlet cabang olahraga apapun. Oleh karena itu mahasiswa Fakultas Ilmu Olahraga (FIO) 2018 terutama bagi mahasiswa Kepelatihan Olahraga yang kedepannya menjadi pelatih harus mengetahui pengetahuan gerak dasar Running ABC ini. Dalam penelitian kali ini analisis gerak dasar Running $\mathrm{ABC}$ akan difokuskan kepada ; pandangan, sikap tubuh, ayunan tangan, dan kaki. Keempat komponen fokus analisis unifikasi ini akan memberikan gambaran sederhana mengenai kesalahankesalahan dasar yang dilakukan oleh mahasiswa saat melakukan Running ABC. Dalam penelitian ini peneliti menjelaskan beberapa kesalahan yang sering dilakukan dalam gerakan Running ABC pada mahasiswa FIO 2018. Kesalahan-kesalahan dasar dalam Running ABC dapat diperbaiki dengan metode unifikasi.Dengan menguasai kunci-kunci metode unifikasi kesalahankesalahan dasar dalam Running ABC akan mudah dilihat dan dapat diperbaiki.

\section{Kesalahan Dasar}

Mahasiswa FIO 2018 masih banyak yang belum menguasai teknik Running $\mathrm{ABC}$ yang baik dan benar. Ini disebabkan di sekolah (SD, SMP, SMA), mahasiswa FIO 2018 tidak pernah diajarkan latihan Running ABC oleh guru. Sekalipun diberikan hanya sekilas saja tidak diberikan teknik yang baik. Atau diberikan ketika ajang olahraga tingkat siswa itu pun hanya sekedarnya saja. Sehingga Mahasiswa FIO 2018 mengalami kesulitan saat tes Running ABC saat perkuliahan. Ini disebabkan karena kemampuan guru tidak semuanya bisa melakukan Running $\mathrm{ABC}$ dengan baik. Dari data penelitian video dan foto latihan yang dikumpulkan mahasiswa Kesalahan dasar yang dilakukan mahasiswa dalam melakukan Running ABC dapat diketahui dari pandangan, ayunan tangan, sikap tubuh, dan kaki/sikap berdiri. Kesalahan dasar ini yang paling sering terjadi saat mahasiswa melakukan praktik Running $\mathrm{ABC}$.

\section{Analisis Running ABC Dengan Metode Unifikasi}

Perlu diingat empat prinsip unifikasi adalah pertahankan titik pusat, berat ada dipermukaan bawah, pancarkan ki. Dengan adanya kunci unifikasi ini bagi mahasiswa yang kesulitan melakukan gerakan Running ABC dapat melakukan gerakan yang paling sulit sekalipun semisal Triple Take Off. Running ABC dengan kuncikunci unfikasi akan menghasilkan otomatisasi dalam bergerak bagi mahasiswa yang belajar dengan teknik yang baik dan benar.

\section{Pandangan}

Dalam melakukan Running ABC mahasiswa masih melakukannya dengan pandangan menunduk. Seharusnya pandangan lurus ke depan. Pandangan 
menjadi kunci dalam melakukan Running ABC. Dalam unifikasi jika menunduk akan memutuskan energi. Yang mengangkibatkan gerak menjadi tidak harmonis.

\section{Sikap Tubuh}

Sikap tubuh yang tidak stabil dapat terlihat jelas saat mahasiswa melakukan gerakan Running ABC. Ini dapat diketahui dari sikap tubuh yang bungkuk, terlalu condong ke depan ataupun terlalu condong ke belakang. Mempertahankan tubuh dalam posisi stabil menjadi kunci dalam melakukan gerak Running ABC.

\section{Ayunan Tangan}

Ayunan tangan saat melakukan Running ABC terlihat tidak simetris. Ini menandakan tangan tidak rileks dan juga mengeluarkan energi yang berlebihan.

\section{Kaki}

Dalam melakukan Running ABC mahasiswa sering tidak memperhatikan kaki dan sikap berdiri. Kesalahan yang sering terjadi kaki lutut tidak simetris, pinggul tidak diangkat. Mahasiswa FIO 2018 juga tidak memperhatikan sikap berdiri yang baik dan benar. Padahal sikap berdiri yang baik dan benar menjadi kunci melakukan teknik Running ABC. Dalam metode Unifiasi berdiri yang baik dan benar sebelum melakukan gerakan Running ABC adalah sikap tubuh berdiri tegak, tapi tetap rileks. Batang leher tegak lurus dan rileks menopang kepala, pandangan lurus ke depan, dan dagu tidak menunduk. Punggung sampai kaki lurus, pinggul diangkat. Saat berdiri tegak dan rileks, kedua lengan dari bahu sampai telapak tangan ada di samping tubuh, sementara kedua telapak kaki dibuka selebar bahu.

\section{Kesimpulan}

Mahasiswa FIO 2018 belum menguasai teknik Running ABC yang baik dan benar. Banyak dari Mahasiswa FIO 2018 yang tidak diajarkan teknik Running ABC oleh guru-guru olahraga di sekolah. Sekalipun diajarkan untuk pertandingan dan perlombaan hanya diajarkan sekadarnya saja. Dapat diketahui kesalahan dasar Running ABC pada mahasiswa FIO 2018 dilihat dari pandangan, sikap tubuh, ayunan tangan dan kaki. Seharusnya Mahasiswa FIO 2018 wajib memiliki kemampuan teknik Running $\mathrm{ABC}$ sebagai calon pelatih ataupun guru di sekolah. Bagi pelatih dan guru harus menguasai, memperhatikan dan mampu mengevaluasi cara bagaimana teknik Running $\mathrm{ABC}$ yang baik dan benar.

\section{DAFTAR PUSTAKA}

Suharsimi, Arikunto. (2010). Prosedur Penelitian: Suatu Pendekatan Praktik, Edisi Revisi, Cetakan Ketigabelas, Penerbit Rineka Cipta, Jakarta

Priyono, Ali. (2016). Pengaruh Latihan Akselerasi Balance Coordination Running Terhadap Peningkatan Hasil Belajar Lari Cepat Pada Siswa Sekolah Dasar. Jurnal Penelitian Ilmiah pp 3-4

Ramadhanova, Athira. (2019). Running ABC. Diunduh 13 November 2019.

https://www.coursehero.com/file /45257957/running-abc/

Sutopo, H.B (2002). Metodologi Penelitian Kualitatif Dasar Teori dan Terapannya dalam Penelitian. UNS Press. Surakarta

Yudi, Hendrayana. (2007). Bermain Atletik. Fakultas Pendidikan 
Olahraga dan Kesehatan, Universitas Pendidikan Indonesia. Bandung.

Hernawan, H., Sukarya, Y., \& Solahuddin, S. (2019). Locomotor basic motion learning model based on traditional game for basic school students. Journal of Physics: Conference Series, 1318(1). https://doi.org/10.1088/17426596/1318/1/012047

Sarwono, Jonathan. (2006). Metode Penelitian Kuantitatif dan Kualitatif. Graha Ilmu.

Jogjakarta

Moleong, Lexy J. (2005). Metodologi Penelitian Kualitatif. Remaja Rosdakarya.Bandung

Nawawi, Hadari. (2012). Metode Penelitian Bidang Sosial. Gajah Mada University Press. Yogyakarta

Diposumarto, Ngadino Surip, (2012). Metodologi Penelitian Teori dan Terapan. Penerbit Mitra Wacana Media. Jakarta

Prasetyo, Bambang dan Jannah, Miftahul. (2007). Metode Penelitian Kuantitatif Teori dan Aplikasi. PT Raja Grafindo Persada. Jakarta
R.S. Harisenjaya, (1993). Penuntutan Test Kesegaran Jasmani. Refika Aditama : Bandung

Supandi, (1992). Strategi Belajar Mengajar Pendidikan Jasmani Dan kesehatan. Depdikbud. Jakarta

Sugiyono, (2009). Metode Penelitian Kuantitatif dan Kualitatif dan R\&D. Alfabeta.

Bandung

Sujarwo, (2012). Model-Model Pembelajaran Suatu Strategi Mengajar. Yogyakarta

Tohei, Koichi, (2001). Ki In Daily Life. Ki No Kenkyukai. Publication. Japan.

Winarno Surachmad, (1994). Pengantar Interaksi Mengajar-Belajar.Transito. Bandung.

Woeryanto,(1992). Ilmu Kepelatihan Teori dan Metodologi Latihan, Program Pembinaan

Dan Peningkatan Prestasi Olah Raga. FPOK IKIP Jakarta: Jakarta.

Wardianto, (2016). Pengaruh Latihan ABC Running Terhadap Power Tungkai Peserta

Didik Ekstrakurikuler Bola Voli. Jurnal Penelitian Ilmiah. Pp 1-2 